\title{
Cytocompatibility by MTT Assay and Platelet Adhesion of Ti and Ti-6Al-4V coated with Hydroxyapatite in different Plasma Gas Atmospheres
}

\author{
${ }^{1}$ Ravindra Kotian, ${ }^{2} \mathrm{P}$ Prasad Rao, ${ }^{3}$ Prashanthi Madhyastha, ${ }^{4} \mathrm{KL}$ Shobha, ${ }^{5} \mathrm{BS}$ Satish Rao, ${ }^{6} \mathrm{Kishore} \mathrm{Ginjupalli}$
}

\section{ABSTRACT}

Aim: This study was performed to evaluate the biocompatibility of pure titanium and $\mathrm{Ti}-6 \mathrm{Al}-4 \mathrm{~V}$ metals coated with hydroxyapatite $(\mathrm{HA})$ by plasma spray using different plasma gas atmospheres.

Materials and methods: The cell viabilities for each HA-coated sample in an atmosphere of argon, argon-hydrogen, nitrogen, and nitrogen-hydrogen were studied using MTT assay and platelet adhesion test.

Results: The mean cell viabilities by MTT [3-(4,5-dimethylthiazol-2-yl)-2,5-diphenyltetrazolium bromide] assay of samples coated with HA in argon-hydrogen plasma atmosphere showed maximum cell viability at different time intervals compared with other coating atmospheres of argon-hydrogen, nitrogen, and nitrogen-hydrogen. A statistically significant value of cell viability $(p<0.001)$ was observed between and within the groups of argon, argon-hydrogen, nitrogen, and nitrogen-hydrogen plasma gas atmosphere. The platelet adhesion study showed agglomerates of platelet cells in some isolated regions of $\mathrm{HA}$ for all atmospheres.

Significance: The results obtained in this study can serve as a guide for the development of new Ti-based HA-coated implants in different plasma gas atmospheres.

Keywords: Cytocompatibility, Hydroxyapatite, MTT assay, Plasma coating, Platelet adhesion, Titanium, Ti-6Al-4V.

How to cite this article: Kotian R, Rao PP, Madhyastha P, Shobha KL, Rao BSS, Ginjupalli K. Cytocompatibility by MTT Assay and Platelet Adhesion of $\mathrm{Ti}$ and $\mathrm{Ti}-6 \mathrm{Al}-4 \mathrm{~V}$ coated with Hydroxyapatite in different Plasma Gas Atmospheres. World J Dent 2017;8(1):28-36.

Source of support: Nil

Conflict of interest: None

\footnotetext{
${ }^{1,6}$ Associate Professor, ${ }^{2,4,5}$ Professor, ${ }^{3}$ Senior Lecturer

${ }^{1,3,6}$ Department of Dental Materials, Manipal College of Dental Sciences, Manipal University, Mangaluru, Karnataka, India

${ }^{2}$ Department of Metallurgical and Materials Engineering, National Institute of Technology, Surathkal, Karnataka, India

${ }^{4}$ Department of Microbiology, Malaka Manipal Medical College Manipal University, Manipal, Karnataka, India

${ }^{5}$ Department of Radiation Biology and Toxicology, Manipal University, School of Life Sciences, Manipal, Karnataka, India

Corresponding Author: Ravindra Kotian, Associate Professor Department of Dental Materials, Manipal College of Dental Sciences, Manipal University, Mangaluru, Karnataka, India Phone:+918242428716, e-mail: ravindra.kotian@manipal.edu
}

\section{INTRODUCTION}

Commercially, pure titanium (CP-Ti) and Ti-6Al-4V are the most suitable metallic materials as dental and medical implants because these materials exhibit good mechanical properties and have corrosion resistance. ${ }^{1}$ However, vanadium in Ti alloys may dissolve and form harmful metal ions, which have been detected in tissue close to the titanium implant. ${ }^{2,3}$ Materials of good biological properties show a high rate of bone growth and high corrosion resistance in high-chloride-containing body fluid environment. Corrosion of implant material causes minute corrosion products to accumulate in adjacent tissues and stimulate allergy in patients.

The efficiency of metallic implants for biomedical applications can be improved by coating with biocompatible materials. Bioconductive material hydroxyapatite (HA) $\left[\mathrm{Ca}_{10}\left(\mathrm{PO}_{4}\right)_{6}(\mathrm{OH})_{2},(\mathrm{HA})\right]$ is widely used as a coating on the surface of the metals or alloys because they chemically connect the metal/alloy implant and bone. Hydroxyapatite promotes chemical osteointegration through the formation of a light bond with bone due to its similarity to CaP minerals found in bone tissues. Specifically, the biocompatibility of the HA and the osteoconductivity behavior of this ceramic material were confirmed and employed in medicine for more than 25 years. ${ }^{4}$

Hydroxyapatite coatings have been applied by a variety of methods: Dip coating, ${ }^{5,6}$ electrophoretic deposition, ${ }^{7,8}$ hot isostatic pressing, ${ }^{5}$ ion beam sputtering, ${ }^{9}$ ion beam dynamic mixing, ${ }^{10}$ plasma spraying, ${ }^{11}$ conventional flame spraying, ${ }^{12,13}$ and high-velocity oxy-fuel combustion spraying. ${ }^{14}$ Among these, plasma spray appears to be most favorable in terms of chemical control, biocorrosion resistance, ${ }^{15,16}$ process efficiency, ${ }^{2}$ and the degree to which the surface fatigue resistance is reduced. ${ }^{17}$

In plasma-sprayed coatings, the hot gas jet created by plasma arc expands, entrains powder particles, heats the particles, and accelerates them toward the substrate, where they impact, deform, and solidify to form a coating. The high degree of particle melting and relatively high particle velocity of plasma lead to higher deposit densities and bond strength compared with most flame and electric arc spray coatings. The high droplet/substrate adhesion is achieved due to the high particle velocity and deformation that can occur on impact. The inert gas plasma 
jet, ignoring ambient air mixing effects, contributes to lower oxide content than other thermal spray processes.

The ideal HA coating for orthopedic and dental implants would be one with low porosity, strong cohesive strength, good adhesion to the substrate, a high degree of crystallinity, and high chemical purity and phase stability. Depending on the specific application, different materials are used. In some applications, osseointegration behavior is the deciding factor, whereas for some materials in contact with blood, the prevention of platelet adhesion and subsequent clotting is the main focus. For example, endosseous implants initially come into contact with blood. Thus, the nature of the interaction between the blood and implanted endosseous implants may influence bone healing events in the peri-implant healing compartment. Furthermore, mechanical properties like wear, hardness, and elastic modulus can have an important influence on biocompatibility. In the present investigation, studies on the following were conducted:

- Does the coated surface have an influence on the cell viability?

- Do the HA-coated metal substrates modulate platelet activity?

The properties of the coatings are controlled by regulating various plasma spray parameters. Some basic parameters include power, current, distance between nozzle and substrates, plasma work gas rate, and feed rate. The plasma working gas composition remains the same during the plasma spray process and is not generally a basic parameter that changes during the coating process. However, it is considered to be an important parameter that has an influence on coating properties. ${ }^{18}$ For example, argon mixed with hydrogen gives a good coating. But without hydrogen, the powder particles bounce back from the flame instead of entering it. This is because of the high velocity and viscosity of the argon gas. Plasma work gas composition also influences the thickness of the coating. For example, nitrogen as carrier gas results in the thicker coating as compared with the use of argon gas. Therefore, one can expect the plasma gas composition to also play a major role in the properties of HA coating.

A strict plasma control is required to optimize the property of the coating. Many investigators ${ }^{2,16,19-26}$ have studied various processing parameters to understand the phase constitution, porosity, degree of crystallinity, $\mathrm{OH}^{-}$content, microstructure, and surface roughness of the HA coating by regulating the basic spray parameters.

It was therefore planned to study the effect of plasma working gas composition on HA coating keeping in mind the basic parameters of plasma spray technique. The coatings were made on $\mathrm{Ti}$ and $\mathrm{Ti}-6 \mathrm{Al}-4 \mathrm{~V}$ metal substrates. The plasma gas compositions selected in the present study were argon, nitrogen, argon-hydrogen, and nitrogen-hydrogen. The aim of this study was to evaluate the biocompatibility of pure titanium and Ti-6Al-4V metals coated with HA by plasma spray using different plasma gas atmospheres.

\section{MATERIALS AND METHODS}

\section{Plasma Coating}

Plasma spray processing is the process of utilizing plasma flame in order to spay various coating materials onto metal substrates. In this plasma is a stream of gas, i.e., made luminous as a result of heat. This luminous plasma flame is used to coat the powder onto the substrate metal by fusion. In the present study, plasma coating of HA procured from Plasma Biotal Limited, UK (Capital 30 Batch P253/0116) was given on CP Ti (ASTM B 348 Gr. 1), hereafter called Ti 12, and Ti-6Al-4V (ASTM B 348 Gr. 5), hereafter called Ti 31 metal substrates. The metallic samples of dimension $100 \times 6 \times 4$ mm were prepared from the rods of Ti 12 and Ti 31 received from Mishra Dhatu Nigam Ltd., Hyderabad, India. The coating was done at Spraymet Surface Technologies Pvt. Ltd., Bengaluru, India. The surface of the substrate metal was roughened before coating for better bonding between the metal substrate and HA coating. Surface roughening was done with grit blasting with $\mathrm{Al}_{2} \mathrm{O}_{3}$ of grit size 24. The roughened Ti 12 and Ti 31 samples were then washed with water, followed by alcohol before plasma coating.

A plasma spray process used a direct current (DC) electric arc to generate a stream of high-temperature ionized plasma gas. The arc was struck between a tungsten cathode and a copper anode within the torch. The torch was fed with a continuous flow of inert gas, which was ionized by the DC arc, and was compressed and accelerated by the torch nozzle so that it issues from the torch as a high-velocity (in excess of $800 \mathrm{~m} / \mathrm{sec}$ ), high-temperature (12,000-16,000 K) plasma jet. The coating material in the powder form was carried in an inert gas stream into the plasma jet where it was heated and propelled toward the substrate. The coating was carried out separately using four gas atmospheres: Argon, argon-hydrogen, nitrogen, and nitrogen-hydrogen. Here argon and nitrogen served as primary gas and hydrogen acted as a secondary gas. A pressure of $0.76 \mathrm{MPa}$ for the primary gas (argon and nitrogen) and $0.069 \mathrm{MPa}$ for the secondary gas of $10 \%$ volume (hydrogen) was applied to get the desired plasma jet. The stand-off distance between the substrate and the jet was maintained at $8 \mathrm{~cm}$ till achievement of the desired coating thickness of $100 \mu \mathrm{m}$.

\section{Toxicity Evaluation}

In vitro evaluation of any biomaterial is very important in order to understand the cell viability of the material 
before actual usage. In the present study of toxicity evaluation, specimens of dimension $6 \times 4 \times 4 \mathrm{~mm}(\mathrm{n}=6)$ were cut using low-speed Isomet Buehler precision cutting instrument from all HA-coated and -uncoated samples for cell viability by MTT (3-(4,5-dimethylthiazol2-yl)-2,5-diphenyltetrazolium bromide) assay (Sigma Chemical Co.).

\section{MTT Assay}

The test was carried out according to the protocol described by Mosmann. ${ }^{27}$ It is a simple colorimetric test for cell proliferation and survival, which is used for the measurement of cytotoxicity. The assay involves the ability of viable cells to convert a soluble tetrazolium salt MTT into the purple formazan end product by mitochondrial dehydrogenase enzymes. The purple color reaction is used as a measure of cell viability.

Exponentially growing V79 cells $\left(10^{4}\right)$ were seeded into 96-well plates and incubated for 24 hours at $37^{\circ} \mathrm{C}$ in $\mathrm{CO}_{2}$. Eight wells each served as a control, blank, and rest of the wells were used for different test samples. The culture medium was removed and substituted with fresh medium with different test samples labeled as 1, 2, 3, 4, 5, 6, 7, 8, 9, 10 for Ti 12 argon, Ti 31 argon, Ti 12 argon-hydrogen, Ti 31 argon-hydrogen, Ti 12 nitrogen, Ti 31 nitrogen, Ti 12 nitrogen-hydrogen, Ti 31 nitrogen-hydrogen, $\mathrm{Ti}$ 12, and $\mathrm{Ti} 31$ respectively, for 24,48 , and 72 hours. After that, $100 \mu \mathrm{L}$ of the MTT stock $(1 \mathrm{mg} / \mathrm{mL})$ was added to each of the 96 wells followed by 4 -hour incubation at $37^{\circ} \mathrm{C}$ in a $5 \% \mathrm{CO}_{2}$ atmosphere. The test samples were removed from the medium and purple-colored precipitate of formazan was solubilized by dissolving in a $100 \mu \mathrm{L}$ buffer consisting of $23 \%$ sodium dodecyl sulfate in $50 \% \mathrm{~N}, \mathrm{~N}$-dimethyl formamide ( $\mathrm{pH}$ 4.7). Greater magnitude of optical density (OD) due to intense purple coloring is regarded as showing higher cell viability. After 5 to 10 minutes of incubation at $37^{\circ} \mathrm{C}$, the ODs were read on a multiwell spectrophotometer (Tecan, Austria) at $540 \mathrm{~nm}$ wavelength. Percent viability was calculated as follows:

$$
\begin{aligned}
& \text { Average of test (OD) - } \\
& \text { Percent viability }=\frac{\text { Average of blank }(O D)}{\text { Average of control }(O D)-} \times 100 \\
& \text { Average of blank (OD) }
\end{aligned}
$$

\section{Platelet Adhesion Study}

The activation of platelet in contact with any biomaterial affects the healing process, and it is a function of microtexture, composition, and other parameters. Platelet adhesion is an initial, crucial, and complex matter. Activation and adhesion of platelet play a fundamental role in the development of thrombosis. For the platelet adhesion study, specimens of dimension $6 \times 4 \times 4 \mathrm{~mm}$ were cut from uncoated Ti 12 and Ti 31 and also from HA plasma-coated samples of argon, argon-hydrogen, nitrogen, and nitrogen-hydrogen $(n=6)$. The uncoated Ti 12 and Ti 31 samples' surface was polished by initially grinding with successively finer Emery papers and finally polished on a disk using lavigated alumina. All the test samples were cleaned in acetone and ethyl alcohol solution for 5 minutes, and finally rinsed with distilled water and dried.

Methodology of Platelet Adhesion Blood adhesion tests were conducted in a class 10,000 clean room. ${ }^{28}$ The samples were evenly distributed in two culture dishes; $200 \mathrm{~mL}$ blood (containing $3.8 \mathrm{~mL} \mathrm{wt} \%$ citrate solution, blood/citrate acid = 9:1) extracted from a healthy adult was centrifuged to form a platelet-rich plasma (PRP) and erythrocyte. The PRP contained about 30-35 $\times 10^{7}$ platelets/ $\mathrm{mL}$. Then the blood was poured into culture dishes. After culturing at $37^{\circ} \mathrm{C}$ for 30 minutes and 3 hours respectively, the PRP was taken out of the wells. A phosphate-buffered solution was added to the wells and gently rinsed 2 to 3 times to get rid of platelets adsorbed nonspecifically on the surface. Then the samples were soaked in $2 \%$ glutaraldehyde for 1 hour and 5\% glutaraldehyde for 12 hours to fix the platelets, which adhered specifically on the surface. After rinsing with distilled water, the samples were subsequently dehydrated through $50,75,90$, and $100 \%$ ethanol-water solutions twice for 10 minutes each. After dehydrating, the samples were subsequently dealcoholized through 50,75, 90, and 100\% isoamyl acetate water solution twice for 10 minutes each. The samples were dried at a critical point overnight. After sputter coating with platinum, the surfaces of the samples were observed under scanning electron microscopy, and the photographs of the platelets were randomly taken from the scanned field.

\section{RESULTS}

\section{Toxicity Evaluation by MTT Assay}

The aim of this study was to evaluate the cytotoxicity of uncoated and coated Ti 12 and Ti 31 in different gas atmospheres. The results of cell viability at 24,48 , and 72 hours are presented in Graphs $1 \mathrm{~A}$ to $\mathrm{C}$. The statistical analysis was done by students unpaired t-test using Statistical Package for the Social Sciences (SPSS) vession 17.0 software, which is presented in Table 1. Maximum cell viability was observed for the argon-hydrogen atmosphere at different time intervals.

\section{Platelet Adhesion Study}

The platelet adhesion on coated and uncoated samples exposed to 30 minutes and 3 hours is shown in sets of Graphs $1 \mathrm{~A}$ to $\mathrm{C}$, Figs $1 \mathrm{~A}$ to $\mathrm{H}$, and $2 \mathrm{~A}$ to $\mathrm{H}$. Platelet 

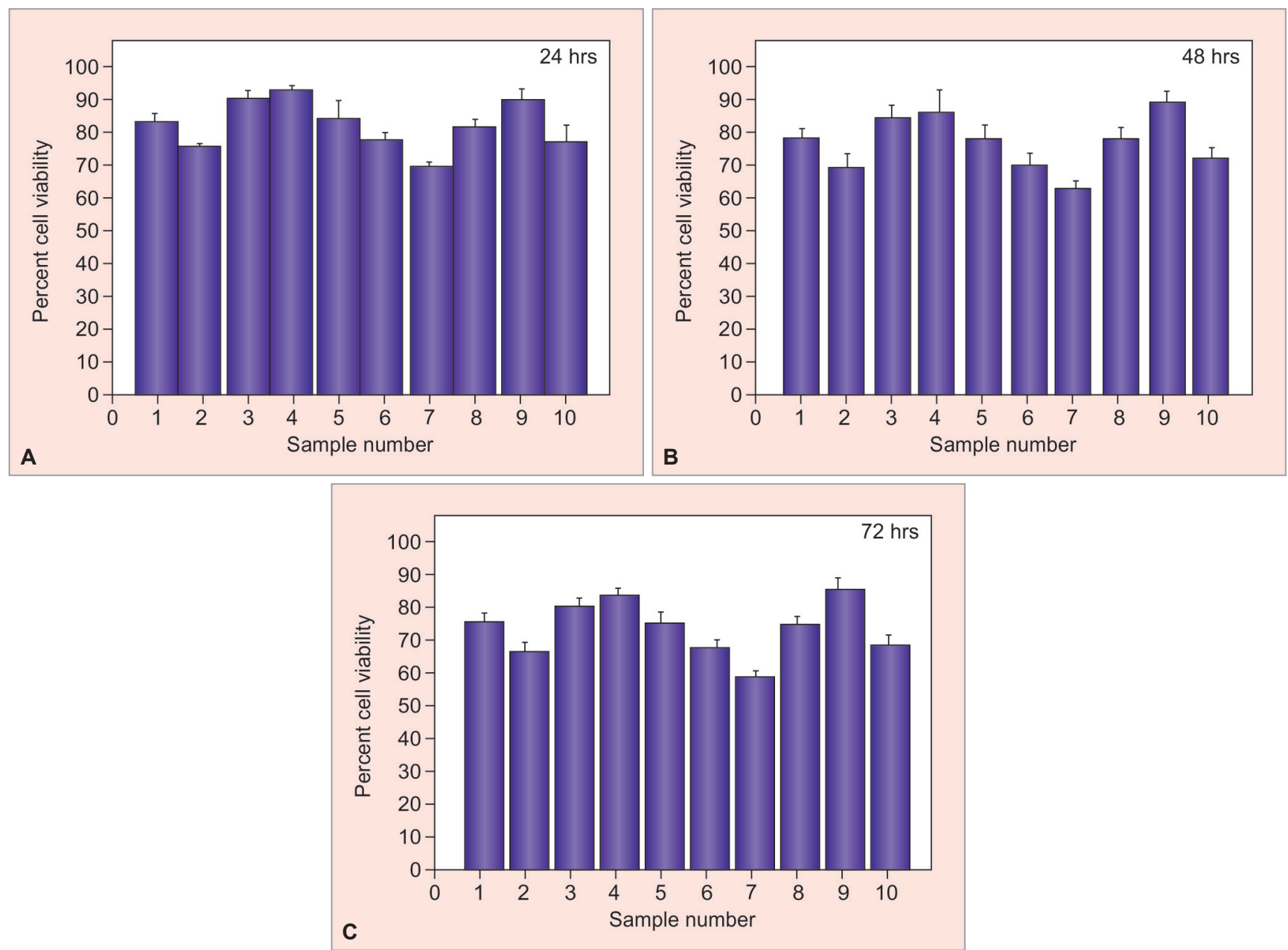

Graph $1 \mathrm{~A}$ to C: Toxicity evaluation of HA-coated and -uncoated specimen at 24,48 , and 72 hours

adhesion was found in some areas of the coating that were soaked in PRP for 30 minutes and 3 hours. Uncoated samples showed more platelet activation as compared with coated samples, with an increase in the soaking period.

\section{DISCUSSION}

\section{Toxicity Evaluation by MTT Assay}

The decomposition of HA owing to extremely hightemperature subjection during plasma coating causes complicated phase compositions in the coatings including crystalline and amorphous HA, calcium phosphates, such as tricalcium phosphate and tetracalcium phosphate, and calcium oxide. These impurities can lower the bioactivity of HA coating. The MTT assay is one such test through which the toxicity evaluation of the material can be tested by cell viability measurement.

Graphs $1 \mathrm{~A}$ to $\mathrm{C}$ shows the comparative cytotoxic effect of various test samples' treatment on V79 cells in vitro at 24,48 , and 72 hours. There was time-dependent decrease in the cell death as indicated by a decrease in OD in those wells treated with different test samples. The percent cell viability was found to be more in the samples coated with HA in the argon-hydrogen atmosphere on Ti 12 (sample code 3) and Ti 31 (sample code 4) compared with other test samples. The uncoated Ti 12 (sample code 9) also showed higher cell viability compared with other groups (argon, nitrogen, and nitrogen-hydrogen) at the tested time periods. Lower values of cell viability of samples coated in the atmospheres of argon, nitrogen-hydrogen, and nitrogen were observed.

The statistical analysis of the results as shown in Table 1 showed statistically high significant value $(p<0.001)$ for all coating atmospheres at different time intervals within and between the groups. The mean cell viability was found to be highest in the case of HA coated in the argon-hydrogen atmosphere, which is above $90 \%$ at 24 hours and above $80 \%$ at 48 and 72 hours. However, there was time-dependent decrease in cell death in all the samples coated with HA in different atmospheres as well as uncoated Ti 12 and Ti 31.

The reason for showing high cell viability in the case of argon-hydrogen plasma coating atmosphere may be attributed to the inert nature of primary plasma gas 


\begin{tabular}{|c|c|c|c|c|c|c|c|}
\hline Groups & Class & & $n$ & Mean & Std. Deviation & F-value & $p$-value \\
\hline \multirow[t]{6}{*}{ I } & Ar-Ti 12 & 24 hours & 6 & 83.500 & 1.049 & 128.478 & $<0.001$ \\
\hline & & 48 hours & 6 & 78.167 & 0.753 & & \\
\hline & & 72 hours & 6 & 75.833 & 0.753 & & \\
\hline & Ar-Ti 31 & 24 hours & 6 & 76.500 & 1.049 & 166.689 & $<0.001$ \\
\hline & & 48 hours & 6 & 70.833 & 0.753 & & \\
\hline & & 72 hours & 6 & 67.000 & 0.894 & & \\
\hline \multirow[t]{6}{*}{ II } & $\mathrm{Ar} / \mathrm{H}-\mathrm{Ti} 12$ & 24 hours & 6 & 90.500 & 1.049 & 203.790 & $<0.001$ \\
\hline & & 48 hours & 6 & 84.167 & 0.753 & & \\
\hline & & 72 hours & 6 & 81.000 & 0.632 & & \\
\hline & $\mathrm{Ar} / \mathrm{H}-\mathrm{Ti} 31$ & 24 hours & 6 & 93.000 & 0.632 & 180.326 & $<0.001$ \\
\hline & & 48 hours & 6 & 88.833 & 0.753 & & \\
\hline & & 72 hours & 6 & 85.167 & 0.753 & & \\
\hline \multirow[t]{6}{*}{ III } & NTi 12 & 24 hours & 6 & 84.333 & 1.033 & 103.941 & $<0.001$ \\
\hline & & 48 hours & 6 & 78.667 & 0.816 & & \\
\hline & & 72 hours & 6 & 76.500 & 1.049 & & \\
\hline & N-Ti 31 & 24 hours & 6 & 77.833 & 0.753 & 263.922 & $<0.001$ \\
\hline & & 48 hours & 6 & 70.833 & 0.753 & & \\
\hline & & 72 hours & 6 & 68.167 & 0.753 & & \\
\hline \multirow[t]{6}{*}{ IV } & N/H-Ti 12 & 24 hours & 6 & 69.500 & 1.049 & 280.574 & $<0.001$ \\
\hline & & 48 hours & 6 & 62.667 & 0.816 & & \\
\hline & & 72 hours & 6 & 58.333 & 0.516 & & \\
\hline & $\mathrm{Ni} / \mathrm{H}-\mathrm{Ti} 31$ & 24 hours & 6 & 83.000 & 0.894 & 136.311 & $<0.001$ \\
\hline & & 48 hours & 6 & 78.667 & 0.816 & & \\
\hline & & 72 hours & 6 & 75.167 & 0.753 & & \\
\hline \multirow[t]{6}{*}{ V } & Ti 12 & 24 hours & 6 & 90.833 & 0.753 & 30.064 & $<0.001$ \\
\hline & & 48 hours & 6 & 88.833 & 0.753 & & \\
\hline & & 72 hours & 6 & 86.667 & 1.211 & & \\
\hline & Ti 31 & 24 hours & 6 & 78.667 & 0.816 & 121.250 & $<0.001$ \\
\hline & & 48 hours & 6 & 73.000 & 1.549 & & \\
\hline & & 72 hours & 6 & 68.667 & 0.816 & & \\
\hline
\end{tabular}

argon and the reducing nature of the secondary gas hydrogen. In such inert and reducing atmosphere, there is less chance of material undergoing chemical changes due to oxidation.

\section{Platelet Adhesion Study}

Many studies ${ }^{29-31}$ have shown that HA-coated endosseous implants exhibit more implant bone formation and more bone contact at early healing times than uncoated ones. In order to determine the change in potential blood compatibility because of structural changes that have taken place during the coating at different atmospheres, platelet adhesion studies were selected. Platelet adhesion is one of the most important steps during blood coagulation on the artificial surface. This test is used to evaluate the antithrombus of biomaterials through observing the state of platelets on the surface of biomaterials. If the substance used is biocompatible, then the platelet adhering to it should be minimal or negligible. This is because the platelets always adhere to substances which are foreign in nature. This is a protective phenomenon to remove any foreign body. Platelets activate the coagulation system in which the fibrinogen is covered with fibrin, which is seen as fibrin thread. It has also been reported ${ }^{32}$ that an increase in the complexity of surface microstructure enhances platelet adhesion activation on titanium. For this reason, polishing the surface of a titanium metal to a mirror surface has been expected to be the reasonable method to improve thromboresistance. ${ }^{33}$

The present study involves the influence of plasma gas composition on the blood compatibility of HA coating. Upon scanning, the entire surface of all the coated samples soaked in PRP for 30 minutes as well as 3 hours showed only some isolated regions of platelet adhesion. Some of the isolated regions where platelets were found in coated samples that were dipped for a period of 30 minutes in PRP are presented in Graphs 1A to C. Figures 1A to $\mathrm{H}$ show the platelet adhesion after 3 hours of dipping. From these figures, it can be seen that there was no significant difference in the platelet activation at 30 minutes and 3 hours of soaking period. The platelets were observed in the form of agglomerates with distorted structure. This can be attributed to the rough and complicated structure of HA. Platelet adhesion was also found in the case of uncoated metal samples as shown in Figures $2 \mathrm{~A}$ to $\mathrm{H}$. Since these samples were highly polished, the platelets 

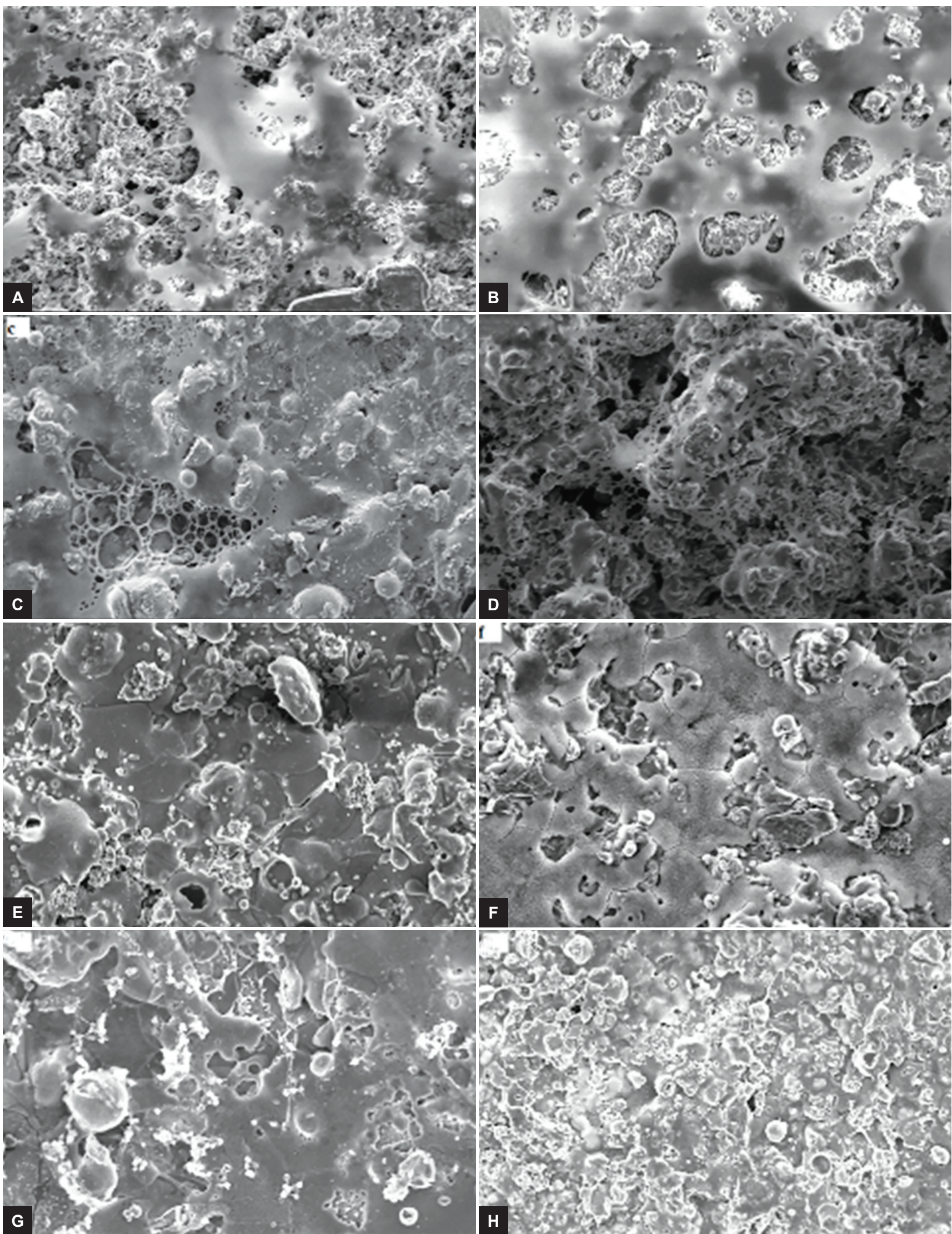

Figs 1A to $\mathrm{H}$ : Platelet adhesion on HA coating after 30 minutes: (A) Ti 12 in argon atmosphere; (B) Ti 31 in argon atmosphere; (C) Ti 12 in argon-hydrogen atmosphere; (D) Ti 31 in argon-hydrogen atmosphere; (E) Ti 12 in nitrogen atmosphere; (F) Ti 31 in nitrogen atmosphere; (G) Ti 12 in nitrogen-hydrogen atmosphere; and (H) Ti 31 in nitrogen-hydrogen atmosphere 


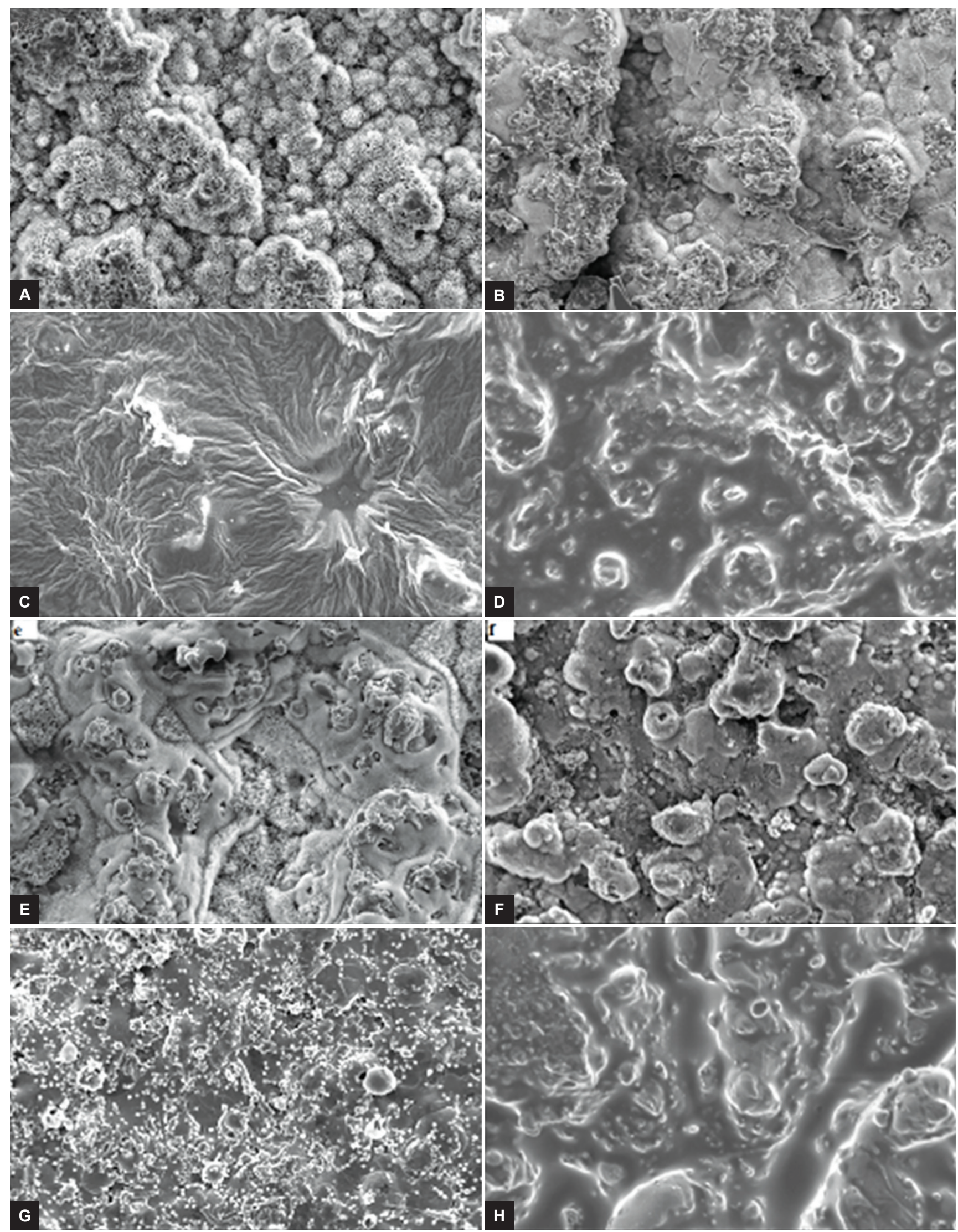

Figs 2A to H: Platelet adhesion on HA coating after 3 hours: (A) Ti 12 in argon atmosphere; (B) Ti 31 in argon atmosphere; (C) Ti 12 in argon-hydrogen atmosphere; (D) Ti 31 in argon-hydrogen atmosphere; (E) Ti 12 in nitrogen atmosphere; (F) Ti 31 in nitrogen atmosphere; $(\mathrm{G}) \mathrm{Ti} 12$ in nitrogen-hydrogen atmosphere; and $(\mathrm{H}) \mathrm{Ti} 31$ in nitrogen-hydrogen atmosphere 


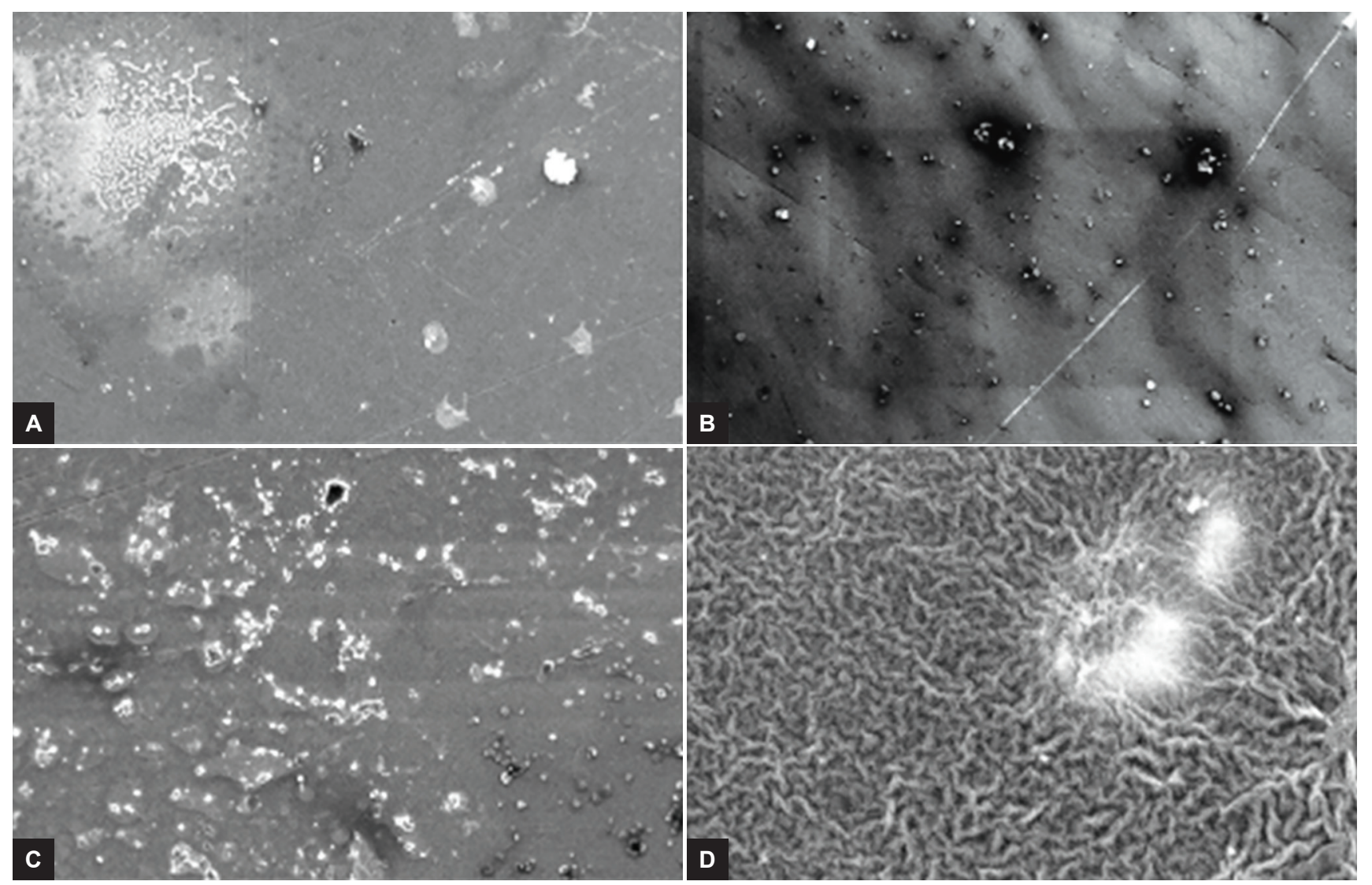

Figs 3A to D: Platelet adhesion on uncoated sample: (A) Ti 12 after 30 minutes; (B) Ti 31 after 30 minutes; (C) Ti 12 after 3 hours; and (D) Ti 31 after 3 hours

observed were found to be spherical compared with HA-coated samples. Uncoated samples showed increased platelet activation with time. More platelet activation at 3 hours of soaking in PRP was observed in the case of Ti 31 as compared with Ti 12, which can be seen from Figures $3 \mathrm{~A}$ to D for Ti 12 and Ti 31 respectively.

Because of the complex nature and rough surface of HA, quantification with respect to cell count and size could not be carried out. In coated samples, the platelets were found to be distorted and in the form of agglomerations. Therefore, in the present study, only qualitative analysis was carried out. The results of the present study indicated that the samples coated under different atmospheres did not significantly affect the platelet adhesion and were effective in suppressing the adhesion to, and activation of platelets on, Ti 12 and Ti 31. No significant change in platelet activation was also observed in coated samples upon increasing the soaking period to 3 hours. The surface microtopography of the coating was responsible for platelet activation rather than the presence of HA or the atmospheres under which the HA coatings were carried out.

\section{CONCLUSION}

Taking into consideration the limitations related to the present study, the following can be concluded:
- Cell viability is better when HA is coated in the argon-hydrogen plasma atmosphere.

- The plasma coating atmosphere has a significant influence on cell viability.

- The plasma coating atmosphere has no influence on platelet activation.

- Platelet activation is dependent on the surface microtopography of the HA on the substrate metal.

- Increase in platelet activation with fibrin formation occurs in uncoated Ti 12 and Ti 31 with an increase in the soaking period with PRP.

\section{REFERENCES}

1. Breme J, Schulte W, Froes FH, Caplan IL. Development of endosseous implants on the base titanium alloys with improved functionality. In: Donath K, editor. The minerals, metals and materials society, Titanium 92 Science and Technology, San Diego, CA; 1992. p. 2757-2764.

2. Morks MF, Kobayashi A. Influence of spray parameters on the microstructure and mechanical properties of gas-tunnel plasma sprayed hydroxyapatite coatings. Mater Sci Eng 2007;B139:209-215.

3. Meachim G, Williams DF. Changes in nonosseous tissue adjacent to titanium implants. J Biomed Mater Res 1973 Nov;7(6):555-572.

4. Hing KA, Best SM, Bonfield W. Characterization of porous hydroxyapatite. J Mater Sci Mater Med 1999 Mar;10(3): 135-145. 
5. Lacefield WR. Hydroxyapatite coating. Ann NY Acad Sci 1998;523:72-80.

6. Li TT, Lee JH, Kobayashi T, Aoki H. Hydroxyapatite coating by dipping method and bone bonding strength. J Mater Sci Mater Med 1996;7:355-357.

7. DucheyneP, RaemdonckWV,HeughebaertJC,HeughebaertM. Structural analysis of hydroxyapatite coating on titanium. J Am Ceramic Soc 1984;6B:381-384.

8. Raemdonck WV, Ducheyne P, Meester PD. Auger electron spectroscopic analysis of hydroxyapatite coating on titanium. J Am Ceramic Soc 1984;63:381-384.

9. Ong JI, Lucas LC. Post-deposition heat treatments for ion beam sputter deposited calcium phosphate coating. Biomaterials 1994 Apr;15(5):337-341.

10. Yoshinari M, Ohtsuka Y, Derand T. Thin hydroxyapatite coating produced by the ion beam dynamic mixing method. Biomaterials 1994 Jun;15(7):529-535.

11. Berndt CC, Haddad GN, Farmer AJD, Gross KA. Thermal spraying for bio ceramic applications. Mater Forum 1990;14: 161-173.

12. Bortz SA, Onesto EJ. Flame sprayed bio ceramics. Am Ceramic Soc Bull 1975;52:898.

13. Weinlaender MJB III, Kenney EB, May PK. Raman microprobe investigation of the calcium phosphate phases of three commercially available plasma-flame sprayed hydroxyapatite coated dental implants. J Mater Sci Mater Med 1992;3:397-401.

14. Haman JD, Lucas LC, Crawmer D. Characterization of high velocity oxy-fuel combustion sprayed hydroxyapatite. Biomaterials $1995 \mathrm{Feb}$;16(3):229-237.

15. Lin JHC, Liu ML, Ju CP. Structure and properties of hydroxyapatite bioactive glass composites plasma sprayed on Ti-6Al-4V. J Mater Sci Mater Med 1994;3:279-283.

16. Cizek J, Khor KA, Prochazka Z. Influence of spraying conditions on thermal and velocity properties of plasma sprayed hydroxyapatite. Mater Sci Eng 2007;C27:340-344.

17. Brossa F, Cigada A, Chiesa R, Paracchini L, Consonni C. Adhesion properties of plasma sprayed hydroxyapatite coatings for orthopedic prosthesis. Biomed Mater Eng 1993 Fall;3(3):127-136.

18. Yaszemski MJ, Trantola DJ, Lawandrowski KU, Hasirci V, Altobelll DE, Wise DL. Biomaterials in orthopaedics. Basel: Marcel Dekker; 2004. p. 401-423.

19. Tsui YC, Doyle C, Clyne TW. Plasma sprayed hydroxyapatite coatings on titanium substrates. Part 1: Mechanical properties and residual stress levels. Biomaterials 1998 Nov;19(22): 2015-2029.
20. Sun L, Christopher CB, Clare PG. Phase, structural and microstructural investigations of plasma sprayed hydroxyapatite. Mater Sci Eng 2003;360A:70-84.

21. Sun R, Li M, Lu Y, An X. Effect of titanium and titania on chemical characteristics of hydroxyapatite plasma-sprayed into water. Mater Sci Eng 2006;26C:28-33.

22. Tsui YC, Doyle C, Clyne TW. Plasma sprayed hydroxyapatite coatings on titanium substrates. Part 2: Optimisation of coating properties. Biomaterials 1998 Nov;19(22):2031-2043.

23. Morks MF, Kobayashi A. Effect of gun current on the microstructure and crystallinity of plasma sprayed hydroxyapatite coatings. Appl Surf Sci 2007 Jun;253(17):7136-7142.

24. Morks MF, Kobayashi A. Influence of gas rate on the microstructure and mechanical properties of hydroxyapatite coatings fabricated by gas tunnel type plasma spray. Surf Coat Technol 2006;201:2560-2566.

25. Morks MF, Fahim NF, Kobayashi A. Structure, mechanical performance and electrochemical characterization of plasma sprayed $\mathrm{SiO}_{2}$ /Ti-reinforced hydroxyapatite biomedical coatings. Appl Surf Sci 2008;255:3426-3433.

26. Guo-Liang Z, Guang-Wu W, Kun W. Influence of processing parameters and heat treatment on the phase composition and microstructure of plasma sprayed hydroxyapatite coatings. Trans Nonferrous Met Soc China 2009;19:463-469.

27. Mosmann T. Rapid colorimetric assay for cellular growth and survival: application to proliferation and cytotoxicity assays. J Immunol Methods 1983 Dec 16;65(1-2):55-63.

28. Ren Y, Yang K, Zhang B. In vitro study of platelet adhesion on medical nickel-free stainless steel surface. Mater Lett 2005; 59:1785-1789.

29. Vercaigne S, Wolke JG, Nert I, Jansen JA. A historical evaluation of $\mathrm{TiO}_{2}$-gritblasted and $\mathrm{Ca}-\mathrm{P}$ magnetron sputter coated implants placed into the trabecular bone of the goat: part 2 . Clin Oral Implants Res 2000 Aug;11(4):314-324.

30. Hulshoff JE, Jansen JA. Initial interfacial healing events around calcium phosphate (Ca-P) coated oral implants. Clin Oral Implants Res 1997 Oct;8(5):393-400.

31. Scharnweber D, Dard M, Robetaler S, Sewing A, Hutmann C. Biological performance of biomimetic calcium phosphate coating of titanium implants in the dog mandible. J Biomed Mater Res A 2003 Feb 1;64(2):225-234.

32. Park JY, Cynthia HG, John ED. Platelet interactions with titanium: modulation of platelet activity by surface topography. Biomaterials 2001 Oct;22(19):2671-2682.

33. McCarthy PM, Smith WA. Mechanical circulatory support-a long and winding road. Science 2002 Feb 8;295(5557):998-999. 